\title{
Child Welfare Services Response to COVID-19: Addressing Face-to- Face Contacts
}

\author{
Kristen D. Seay $\mathbb{1 0}^{1} \cdot$ Amanda Stafford McRell ${ }^{1}$
}

Accepted: 3 June 2021 / Published online: 16 June 2021

(C) The Author(s), under exclusive licence to Springer Science+Business Media, LLC, part of Springer Nature 2021

\begin{abstract}
During the onset of the COVID-19 pandemic, child welfare case managers faced contradictions in their responsibility to make regular in-person contact with children and families to promote safety, permanency, and well-being while following public health directives to avoid social contact in order to curb COVID-19 infections. In response, federal guidance was issued regarding the use of technology to maintain mandated contacts with children in foster care. States had to make decisions about how to handle other contact types. This study reviewed documentation of state child welfare agency practices regarding face-to-face contact between case managers and child-welfare involved families between March 2020 and May 2020. Using a point-in-time search to obtain publicly accessible documents related to caseworker face-to-face contact and COVID-19, data was located for 49 states and the District of Columbia $(n=50)$. Documents were analyzed in NVIVO 12 using document analysis. Within the context of face-to-face interactions by child welfare case managers, documents were analyzed in six themes based on the types of services provided to children and families: (1) investigations, (2) family preservation, (3) family team meetings, (4) foster care, (5) adoption, and (6) general child welfare. State decisions about how to manage these contacts varied. In several states case managers were directed to document both virtual and inperson contacts during this time as face-to-face; which may impact future evaluations of child welfare systems during COVID-19. Findings highlight a range of strategies used by state child welfare systems. By reviewing previous practice and hearing what other states are doing, child welfare service agencies have the potential to evaluate appropriately, strengthen their plans and address disparate impacts.
\end{abstract}

Keywords Child protective services $\cdot$ Child welfare $\cdot$ COVID-19 $\cdot$ Policy $\cdot$ Foster care

\section{Highlights}

- This document analysis examines how U.S. child welfare agencies addressed contacts during the early COVID-19 pandemic.

- Some states encouraged virtual contact to meet face-to-face standards, other states encouraged making in-person contacts.

- Differences were found in what a quality contact looked like and what technology could be used to make that contact.

- With low levels of federal guidance on the matter, states had to develop new strategies quickly in order to serve families.

Kristen D. Seay

kdseay@mailbox.sc.edu

1 College of Social Work, University of South Carolina, 1512 Pendleton Street, Hamilton College, Columbia, SC, USA

\section{Background}

Over 672,000 children and families are involved with the US child welfare system annually and an average of 424,000 children are in US foster care on a typical day (Adoption and Foster Care Analysis and Reporting System, 2020). Children become involved with the child welfare system most often due to reports of child maltreatment (child abuse or neglect). If a maltreatment case is substantiated and children are in danger of imminent harm, 
children then experience the additional trauma of being separated from their family of origin to enter foster care or kinship care (Bruskas, 2008; Turney \& Wildeman, 2017). The US child welfare system is a complex network of federal and state agencies that coordinate with other human service organizations embedded in local communities. These groups provide services for families reported for child maltreatment, families at-risk of child removal, families whose children remain in the home and receive services, families with children in foster care, and children who have found permanency through reunification with their families of origin or through adoption (Children's Bureau, 2020).

Child welfare case managers, sometimes referred to as caseworkers, are responsible for ensuring the safety, health and well-being of child welfare-involved children. Their work involves consistent face-to-face meetings with children in foster care, in-person participation in family team meetings and visiting congregate care facilities, foster parent homes and family of origin homes to ensure safety and promote permanency (Administration for Children and Families $[\mathrm{ACF}], 2007)$. Child welfare case managers are also responsible for following health and safety best practices in all their interactions with children and families (ACF, 2007).

\section{Context of Providing Child Welfare Services Amidst COVID-19}

COVID-19, also called Coronavirus disease 2019, is an infectious disease caused by Severe Acute Respiratory Syndrome Coronavirus 2 (SARS-CoV-2) (World Health Organization, 2020). The COVID-19 respiratory virus is primarily spread through person-to-person contact and may be spread by asymptomatic carriers, which makes it highly contagious (Centers for Disease Control and Prevention [CDC], 2020b). At present (April 2021) 564,000 people in the U.S. have died of COVID-19 and over 31.4 million people in the U.S. have been diagnosed with COVID-19 (CDC, 2020a; Worldometer, 2020). COVID-19 is particularly dangerous for people 65 years and older and people of all ages with underlying medical conditions (CDC, 2020c). Children who have the COVID-19 virus may be more likely to develop Multisystem Inflammatory Syndrome (MIS-C), also known as Kawasaki disease (CDC, 2020b). Children with behavioral health needs, children in foster care, children at risk for maltreatment, children with medical complexity, and children in households with socioeconomic difficulties face higher risks of pandemic-related adversities (Wong et al., 2020).

COVID-19 has impacted daily life extensively, particularly for our most vulnerable families at higher risk for child maltreatment. Families living in poverty are more likely to be reported for child maltreatment (Coulton et al., 2007) and may be more likely to experience adverse outcomes following COVID-19 (Dooley et al., 2020). During this difficult time, vulnerable families are also at risk for losing access to services or a reduction in quality as providers attempt to move services to a virtual format. In the early days of the pandemic (between March 2020 and May 2020), efforts to reduce the viral spread of COVID-19 involved limiting face-to-face contact with human service professionals, including education providers and healthcare providers. Many education systems (including daycares, preschools, elementary, middle, and high schools, community colleges, and universities) transitioned from classroom instruction to virtual homeschool instruction (Van Lancker \& Parolin, 2020). Pediatricians, mental health therapists, physical therapists, and other service providers began offering telehealth and/or virtual services whenever possible (American Academy of Pediatrics, 2020; Lee, 2020; Webster, 2020).

While education and health services are important for all children, youth in the US foster care system have a higher prevalence of unmet health needs which could be potentially exacerbated by these changes to these services (Child Welfare Information Gateway, 2015). Treatments for substance use disorders, mental health, and parenting and early intervention services enhance safety and support families at higher risk for maltreatment (Seay, 2020; Seay et al., 2017; Seay \& Kohl, 2015). Families may be experiencing additional stressors related to high unemployment rates and home schooling. Many states are transitioning back to standardly making in-person contacts with families. However, with the possibility of further COVID-19 spread or stay at home orders in the future, we must examine child welfare practice and how changes in face-to-face contact may impact families under considerable stress.

COVID-19 uniquely impacted areas of the US child welfare system including the experiences of children and families receiving services from these agencies (Cohen \& Bosk, 2020; Emig, 2020; Posick et al., 2020) and children and families at-risk for child welfare system involvement (Boserup et al., 2020; Bryant et al., 2020; Griffith, 2020). During the first few months of the pandemic, the lives of children and families changed quickly in response to rapidly-evolving information about the virus and how it spreads. This early pandemic response had a profound impact on children and families (Prime et al., 2020). Understanding how child welfare systems responded to rapidly-evolving and changing times of crisis may lead to increased understanding of the strongest child welfare systems' response strategies to address health or other crises in the future (Greer et al., 2020). 
The United States Centers for Disease Control (CDC) issued guidance to reduce the spread of COVID-19, including avoiding "person-to-person" contact "between people who are in close contact with one another (within about 6 feet)" and to "Put distance between yourself and other people outside your home, remember that some people without symptoms may be able to spread the virus... keeping distance from others is especially important for people who are at higher risk of getting very sick" (CDC, 2020c, pp. 1-2). These health and safety guidelines were inconsistent with child welfare policies and practices related to case manager face-to-face interactions prior to the COVID-19 pandemic.

Within the structure of the US child welfare system, families receive several different types of services that are based upon the responsibilities of child welfare. These child welfare responsibilities are receiving reports of child maltreatment, completing the initial assessment or investigation, providing an assessment of family needs, case planning to meet these needs, service provision by linking families to service or direct service provision, providing family progress assessments, and case closure (DePanfilis \& Salus, 2003). While the organizational structure used to address these child welfare responsibilities varies by jurisdiction, these responsibilities are often provided through investigative services, family preservation services (i.e., ongoing services, permanency services), foster care services, and adoption services units located within a child welfare office. Child welfare case managers meet with families, most commonly face-to-face, to address these responsibilities and provide these services. Once the COVID-19 pandemic began, case managers' in-person, face-to-face interactions with children and families were simultaneously (1) critical to ensure the safety and to promote the wellbeing of US children and (2) potentially likely to spread COVID-19 (CDC, 2020b).

Child welfare case managers provide several different types of contact with families involved with child welfare. First, child welfare case managers must make contact with children in foster care. This form of contact is mandated under federal policy from the Child and Family Services Improvement Act of 2006 (2006), Public law (P.L.) 109288 which requires a minimum of one monthly visit with each child in out-of-home care in order to "ensure child safety, permanency, and well-being" (Capacity Building Center for States, 2017, p. 3). Starting in 2015, provisions in the Child and Family Services Improvement and Innovation Act of 2011 (2011), Public law (P.L.) 112-34 required that at least 50 percent of these monthly visits must be in the home where the child resides. States are required to report these contacts to the federal government. On March 18, 2020, the Administration on Children and Families (ACF) provided additional guidance in the Child Welfare Policy
Manual \$7.3, \#8 (ACF March 18, 2020) regarding these contacts by answering the question, "Does video conferencing between a child in foster care and his/her caseworker meet the Federal statutory provisions at section 422 (b)(17) of the Social Security Act (the Act) for caseworker visits on a monthly $\S$ basis?" The answer was:

In general, no. Videoconferencing or any other similar form of technology between the child and caseworker does not serve as a monthly caseworker visit for the purposes of meeting the requirements of section 422 (b)(17) of the Act. Rather, a monthly caseworker visit must be conducted face-to-face and held in person... However, there are limited circumstances in which a title IV-B agency could waive the in-person aspect of the requirement and permit monthly caseworker visits to be accomplished through videoconferencing. Such circumstances are limited to those that are beyond the control of the caseworker, child, or foster family, such as a declaration of an emergency that prohibits or strongly discourages person-to-person contact for public health reasons $(\$ 7.3, \# 8)$.

On April 5, 2020, a letter from the Associate Commissioner of the Children's Bureau to state child welfare leaders (Milner, April 15 2020) addressed Section 424(f)(2)(A) of the Social Security Act that requires "50 percent of monthly caseworker visits to be in the child's residence" (para. 3). To address changes necessary due to the COVID19 pandemic, "the title IV-E agency may include the monthly caseworker visits that occur by means of video conferencing as "in the child's residence" for meeting the requirement" (p. 2).

Child welfare case managers provide several other types of contact with families involved with child welfare including contact with the parents of children in foster care, contact during an investigation or assessment of allegations of child maltreatment, contact to provide services to families and children who are receiving family preservation services, and contacts related to foster parents or adoption. While face-toface interaction is considered part of a high quality contact (Capacity Building Center for States, 2017), the frequency and standards for these other types of contacts are dictated by child welfare policies at the state or county level. Most U.S. state child welfare agencies set policies at the state-level about how to conduct child welfare work, including the frequency and types of face-to-face contact that are required for child welfare case managers with families served by the agency (Child Welfare Information Gateway, 2018). There are nine states in the U.S. that have a county administered child welfare system and two additional states have a hybrid administered system in which the state and counties share this role (Child Welfare Information Gateway, 2018). 


\section{Current Study}

In March and early April of 2020, child welfare agencies were faced with complex decisions regarding how to provide contacts to address child safety, permanency, and wellbeing while protecting child welfare clients, children in foster care, foster care providers, and staff from the oncoming COVID-19 pandemic. Given the potential impact of this pandemic on child welfare services and the need to better understand service provision under these unusual circumstances, this study examined publicly available documents to address the research question: How did state child welfare agencies address face-to-face contact with children and families during the early stages of the COVID19 pandemic?

\section{Methods}

In order to answer this research question, a document analysis was conducted by the research team (Bowen, 2009; O'Leary, 2014). This analysis followed a process that included: Gathering the texts, Developing an organizational and management scheme, Assessing the authenticity of the documents, Exploring the background information, Asking questions about the documents, and Exploring the content (O'Leary, 2014).

\section{Gathering the Texts and Developing an Organizational and Management Scheme}

The research team started the process by gathering the documents for analysis. Our organizational and management scheme for the retrieval of documents included specifying inclusion and exclusion criteria for the document search (O'Leary, 2014). All analyzed documents were publicly available and retrieved using an online search through Google. Using point-in-time data collection, all publicly available documents were sampled between 5/9/20 and 5/21/20 resulting in accumulated historical statements for some states that did not remove statements as new ones were posted (Shanahan, 2010). For all 50 states, the District of Columbia, and Puerto Rico, a systematic search was conducted to locate information about how each state child welfare agency was handling face-to-face contact with families. The District of Columbia and Puerto Rico will be included in the group term of "state" for the remainder of the paper. Documents were included in the search that met specific inclusion criteria: (1) addressed COVID-19 or coronavirus, (2) discussed face-to-face contact with families, (3) included narrative or text-based information, (4) and available in English. Audio or video messages were inconsistently available and access to record or download these were limited. Thus, audio and video content were excluded from the sample.

\section{Assessing the Authenticity of the Documents}

To address document authenticity, a set process was used to locate documents that fell within the search criteria. For each state, the District of Columbia, and Puerto Rico, the following steps were used to obtain documents until no new documents was located:

1. Locating the state division of child welfare or children's services website and clicking on a banner or heading related to COVID-19 or coronavirus

2. If COVID-19-related banners were not present, using the embedded search engine on the page to search the terms COVID, corona, pandemic, and emergency.

3. Within the child welfare or children's division website, locating the page(s) specific to child protective services, child welfare, and/or child maltreatment and reviewing the relevant page(s) for information on COVID-19 or coronavirus using a banner or embedded search function.

4. Running an internet search with the terms "child welfare" OR "child protective services" AND [state name] AND "COVID-19" OR "coronavirus."

5. Searching within located documents for additional linked documents.

For three states (Montana, West Virginia, Puerto Rico), this search process did not result in any statements or policies released by the state or their partners about COVID-19 and child welfare. No formal documentation or procedures were available for Montana; however, a news article was located that involved interviews of state officials discussing these policies. Since the news article related to child welfare response and COVID-19 met inclusion criteria, the news article was included in this analysis (Rispens, 2020). No information was located for West Virginia during the search. In Puerto Rico, no information was available in English, which excluded them from the study. With the inclusion of the Montana news article, this resulted in a total sample of 49 states and the District of Columbia $(n=50)$. For each state, a single pdf was compiled for analysis with the written documents and text pulled from websites. These pdfs ranged from 1 to 222 pages in length for a total of 2208 pages. These documents were uploaded into NVIVO 12 for analysis.

\section{Exploring the Background Information}

Within a document analysis, it is important consider the intended purpose of the documents included in the analysis 
by exploring the background information available on the document including tone and style (O'Leary, 2014). These documents were intended to provide guidance during an uncertain time, the beginning of the COVID-19 pandemic. Overall, the tone and style of these documents is formal and consistent with official communication from a state-level child welfare agency to both internal and external audiences. This was sometimes signaled through formatting choices like state agency logos and branding. In other cases, letter style documents were sometimes placed on child welfare letterhead and may have even been signed by someone in a state leadership position. While not all documents were this formally formatted, each was posted on websites accessible to the public which indicates that the tone, wording, and style of the document was probably considered before posting.

\section{Asking Questions about the Documents}

O'Leary (2014) describes a process of asking questions about the documents themselves as part of the document analysis. We examined who were the intended audiences of these documents and what were the types of documents. Documents retrieved and extracted for our study included items prepared for a wide variety of audiences including families of origin, foster parents, case managers, provider agencies, and information for the general public. There were many different document types and these included (a) child welfare agency letters often written by the head of the agency, (b) state government announcements, updates, and mandates, (c) frequently-asked questions, meeting minutes, newsletters, and presentations, (d) manuals and how-to guides for case managers, provider agencies, foster parents, and families of origin, (e) resources and materials for foster youth and youth transitioning out of care, (f) family court announcements and mandates for judges and attorneys, and (g) guidelines and resources related to personal protective equipment.

\section{Exploring the content}

The final step in O'Leary's document analysis process is to explore the content of the documents (2014). The first and second authors first went through the documents to code documents for pre-selected larger content areas within child welfare, or themes, that are specific to services that are offered: investigations, family preservation, foster care, and adoption. After this first round of coding for themes, the study team came back together and discussed two other themes that fell outside these categories: (1) general child welfare content applicable to different types of services, (2) specific guidance for family team meetings. Data were then coded into these six themes: (1) investigations, (2) family preservation, (3) family team meetings, (4) foster care, (5) adoption, and (6) general child welfare. The first and second authors then reread documents within each theme to develop inductive codes, or subthemes (Linneberg and Korsgaard 2019). For each theme, the authors discussed the subthemes they observed. These were refined through discussion and then defined. Disagreements were explored by looking at further examples together and clarifying definitions. The first author then went back through the documents to revise the coding based on the agreed upon subthemes and definitions. NVIVO 12 was used for analysis. A conceptual cluster matrix was used to obtain the frequency of themes across states.

\section{Results}

In examining how state child welfare agencies are addressing face-to-face contact with children and families during the early stages of the COVID-19 pandemic, the following six themes were examined based upon the types of services provided to children and families: investigations $(n=$ 35 states), family preservation $(n=30)$, family team meetings $(n=19)$, foster care $(n=41)$, adoption $(n=6)$, general child welfare $(n=43)$.

\section{Investigations}

Child welfare agencies are charged with the assessment or investigation of reports of child maltreatment. Investigations typically involve face-to-face interactions with numerous individuals to assess safety and gather information. Thirty-five states discussed the role of face-to-face contact during the investigative assessment process and how these typically in-person assessment processes would be managed during the earliest stages of the COVID-19 pandemic. No states strictly prohibited face-to-face contact during an investigation when it was necessary to assure child safety. When modifications to in-person contact during investigations were allowed, this fell into three subthemes: COVID-19 confirmed or suspected cases, report severity level, and specific people to interview.

\section{COVID-19 Confirmed or Suspected}

In situations where a family member under child welfare investigation also had a confirmed or suspected case of COVID-19, many states either specifically discussed ways in which in-person child-caseworker/family membercaseworker contact could be modified, or indicated that in-person client-caseworker contact should be modified on a case-by-case basis, to be determined during staffing. For example, in Missouri, if a family member responded 
affirmatively to a screener for COVID-19 the "Investigator should consult with their Supervisor and Circuit Manager" and "must not leave the residence until safety of the child (ren) is assured" (Missouri Department of Social Services: Children's Division, 2020, p. 7). Missouri went on to describe how law enforcement and the State Technical Assistance Team could be called to help address safety and to acquire Personal Protective Equipment (PPE) (Missouri Department of Social Services: Children's Division, 2020). Different types of protective precautions during an investigation were discussed across the sample. These included a question-based screener to conduct with families at intake or during the assessment process $(n=15)$. Additional recommended precautions included the use of PPE generally, or specifically referring to gloves or masks $(n=11)$. States also recommended meeting or conducting interviews outdoors $(n=4)$, handwashing $(n=10)$, or the use of social distancing or standing six feet apart during interviews $(n=14)$.

\section{Report Severity Level}

In some states $(n=10)$, the allegation severity or allegation type determined whether or not virtual means of contact could be allowed during an investigation. These determinations ranged in complexity. In Alaska and Michigan, investigations assigned a priority level 1 or 2 (i.e. highest priority levels) must be assessed in-person (Alaska Department of Health and Social Services, 2020a; Michigan Department of Health and Human Services, 2020). In other states (Indiana, Kentucky), the assigned response time determined which cases were severe enough to require an in-person contact. Cases that were assigned a shorter timeframe for the initial contact at intake required more in-person contact than cases assigned a longer timeframe at intake. In Kentucky, for a case assigned a 48hour or 72-hour response time, rather than a 24-hour response time, initiation of the investigation "should be conducted through other means, not face-to-face contact" (Kentucky Department of Community Based Services, 2020a, para. 3). In Alaska, allegations against a foster care provider must be assessed in-person (Alaska Department of Health and Social Services, 2020a). Similarly, in California, "complaints alleging behavior that seriously endangers the health and/or safety of a child or children in care" needed to be assessed in-person when they involved a foster care provider (California Department of Social Services, 2020b, p. 4).

The type of maltreatment was a factor in determining the contact method in a few states. For example, in Minnesota, virtual contact was allowed in response to reports of educational neglect (Minnesota Department of Human Services, 2020). In New Hampshire, the level of risk assigned at intake was important, but the following types of maltreatment were also considered high risk, particularly when the perpetrator lives in the same home as the child: (1) sexual abuse regardless of age, (2) physical abuse involving children 0-5 years, (3) caregiver substance misuse involving children $0-5$ years, (4) intimate partner violence involving children 0-5 years (New Hampshire Division for Children, Youth, and Families, 2020). North Carolina also identified some case level factors that would encourage a face-to-face response including intimate partner violence, serious substance use or mental health concerns, reports of physical injuries to young children, families with prior cases involving serious child harm or death, families with prior child removals to foster care, and all cases with an immediate response assigned at intake (North Carolina Department of Health and Human Services 2020).

\section{Specific People to Interview}

Some states allowed virtual contact for certain individuals, based on the individual's involvement in the report $(n=13)$. For states that took this approach, the child(ren) designated as the victim(s) were typically required to be seen in-person (e.g., Nebraska, Oregon, Wisconsin). However, there was significant variation in which types of household members and alleged perpetrators required inperson contact rather than virtual contact for interviews. For example, in Oregon, an alleged perpetrator could be interviewed virtually if he or she did not live in the home with the child or have access to the child (Oregon Department of Human Services, 2020). Other children residing in the home who were not identified as a victim could be interviewed virtually in Indiana (Indiana Department of Child Services, 2020a, 2020b). States that described collateral contacts, typically community or family members who are not directly involved in the child welfare case but are able to provide context on the family's well-being, either allowed or encouraged these individuals to be engaged virtually (e.g., California, Indiana, Kentucky, Michigan, Missouri, Ohio, Wisconsin).

In Indiana, interviews were not required to be conducted in the home when the allegations were not specific to the home environment (Indiana Department of Child Services, 2020a, 2020b). There were additional suggestions about the kinds of work that investigators could complete virtually, including safety plan signatures (California), background check submissions (California), follow-up interviews when there are no safety concerns (Colorado, Kentucky, Missouri, Wisconsin), connecting families to their new family preservation case manager (Illinois), and case closures in overdue cases without safety concerns (Missouri). 


\section{Family Preservation}

Consistent with federal guidance (Milner, April 15 2020), family preservation case managers were often extended the option to allow video conferencing to count as face-to-face contact and as contact in the child's residence. There were four subthemes: type of contact, situations requiring inperson contact, promoting child safety, and in-person considerations.

\section{Type of Contact}

Of the 30 states that discussed family preservation or inhome services, more than half $(n=18)$ included documents permitting virtual contact to count for some face-to-face contact with families receiving family preservation services. An additional three states took a stronger stance and encouraged virtual contact or temporarily stopped in-person contact. For example, Kentucky "staff are asked to temporarily suspend normal face-to-face contacts and home visits until further notice, unless there is concern regarding an immediate safety issue" (Kentucky Cabinet for Health and Family Services, 2020, p. 2). There were a few states $(n=3)$ that encouraged face-to-face contact by family preservation case managers. In Oregon, documents indicated that "If possible, monthly in-person face to face contact should still occur for children currently on in-home plans or trial reunifications" (Oregon Department of Human Services, 2020, p. 1).

\section{Situations Requiring In-person Contact}

Numerous states $(n=9)$ specified higher risk family preservation situations that required in-person contact rather than virtual contact. Most commonly, families with a safety plan in place (Idaho, Iowa, Nebraska), those deemed unsafe, but in the home (Arizona), and high-risk cases (Michigan, New Hampshire, New Jersey) all required in-person contact. In Washington, cases with an immediate risk of child removal should be visited in-person (Washington Department of Children, Youth and Families, 2020). There were also descriptions of what should occur if virtual contact raised concerns or if contact could not be made. In Illinois, if a case manager was unable to virtually contact the family for seven days then the caseworker should visit the family in-person (Illinois Department of Children and Family Services, 2020). In Arizona, in-person contact should occur if the family cannot be reached virtually or if there is a nonverbal child in the home and the only method of contact is by telephone (Arizona Department of Child Safety, 2020b). Missouri had the unique approach of using a "curbside check" in which the case manager observes the child in-person but outside of the home to verify safety in cases where the family does not have the ability to participate in a virtual visit (Missouri Department of Social Services: Children's Division, 2020, p. 9).

\section{Promoting Child Safety}

Different strategies were emphasized by states $(n=11)$ regarding virtual contact in ways that they felt promoted child safety. Several states encouraged the use of video methods over telephone contact (Arizona, California, Minnesota, Wisconsin). In Michigan, phone contact was "not sufficient to meet the monthly contact requirement" (Michigan Department of Health and Human Services, 2020 , p. 3). Several states indicated that virtual contact should be held more frequently than in-person contact would have occurred (Illinois, Kentucky, Michigan, Missouri, Ohio, Wisconsin). Case managers were encouraged to obtain private virtual interviews with family members in Idaho and Nebraska.

\section{In-person Considerations}

Similarly, some states $(n=5)$ offered suggestions for how to handle unique situations related to in-person contact. Case managers should announce their visit or call ahead (Arizona, Connecticut, Oregon) due to concerns for COVID-19. Families' preferences for preferring virtual contact to in-person contact were also considered in Colorado and Illinois. The Colorado Office of Children, Youth and Families (2020) provided "guidance and options for required monthly contacts with parents and caregivers during this novel coronavirus pandemic and Colorado's state of emergency. Videoconferencing may be used when there are health concerns related to coronavirus exposure when preferred by the parent/caregiver" (p. 21). For families in Illinois, if contact could not occur because of family's "sickness or health concerns, your caseworker will work with you to identify other ways to allow contact" (Illinois Children and Family Services, 2020, p. 1).

\section{Family Team Meetings}

Nineteen states specifically discussed family team meetings. Family team meetings were a common type of service to hold in virtual format. Eighteen states discussed holding virtual family team meetings as an alternative to in-person meetings. Five of these eighteen states also mentioned the possible use of in-person family team meetings. In Indiana, family team meetings could be conducted at the child welfare office with the approval of the child and family team (Indiana Department of Child Services, 2020a). In Iowa, the decision about the method of the family team meeting (in-person or virtual) was to be determined by the 
family (Iowa Department of Human Services, 2020). Inperson family team meetings then needed to be "less than 10 people" in size (Iowa Department of Human Services, 2020 , p. 4). In Oklahoma, in-person family team meetings could be held if all participants had no symptoms (Oklahoma Human Services, 2020). There was no evidence that any state required in-person family team meetings without a virtual alternative.

\section{Foster Care}

There were 41 states that discussed foster care face-to-face contacts. There were three subthemes: type of contact, access, and virtual contact standards.

\section{Type of Contact}

Of the 41 states discussing foster care contacts, seven states preferred to continue in-person services while implementing precautions like screening, social distancing, and masks. Four states provided insufficient details online to determine their implementation of the ACF's guidance in the Child Welfare Policy Manual §7.3, \#8 (ACF, March 18 2020). The majority of the states $(n=30)$ that discussed foster care face-to-face contacts stated they were supportive of, or preferred, virtual contact between case managers with children in foster care, families of origin, or foster parents. Of these 30 , the majority $(n=17)$ specified criteria in which a case manager should make face-to-face contact with a child or family. These criteria commonly focused on home assessments, initial placements, safety concerns in the placement, and concerns for placement disruption. In a few states, face-to-face caseworker contact might be used initially to help facilitate virtual communication between a child in foster care and the child's birth parent by assisting with technology (Arizona, Washington). In-person visits were also allowed when virtual contact was attempted but could not be made with the child (Missouri, Nebraska).

\section{Access}

A few states $(n=9)$ addressed the ability of child welfare to access children in-person who were located in congregate care facilities. While all states indicated that child welfare cannot be prevented from entering congregate care facilities, they also encouraged the use of virtual contact (Wisconsin, Colorado, Illinois, New Hampshire) or urged child welfare to compromise with the needs of these placement settings (e.g., Ohio). Similarly, there were two states (Alaska, Indiana) that discussed whether or not foster parents could refuse entry to child welfare based on concerns for COVID-19 (Alaska Department of Health and Social Services, 2020b; Indiana Department of Child Services, 2020a). In both states, responses encouraged virtual contact as long as it was sufficient to address child safety concerns.

\section{Virtual Contact Standards}

Virtual contact standards, or state-level recommendations to improve the ability of virtual contact to assess for wellbeing and safety, were located for 27 states. States offered many suggestions for foster care case managers to try and maintain connections with children in foster care. For example, Indiana allowed for the photos of young children's arms, backs, legs, and stomachs to be taken by foster parents and sent to the case managers as one method of ensuring the safety of children (Indiana Department of Child Services, 2020a, 2020b, p. 11). One unique choice to support the needs of children in foster care was implemented by California who presented a program through which youth in foster care could request a cell phone to support their home schooling, family connections, and connections with the case manager (California Department of Social Services, 2020a). Other states, like Minnesota, provided case managers with a list of topics to cover during virtual visits (Minnesota Department of Human Services, 2020). Case managers were also encouraged to try and have private virtual contact with the child (North Dakota, Oregon, Wisconsin) to promote open discussion. In North Dakota, case managers were also told to make sure that children were awake during the virtual visitation to ensure safety (North Dakota Department of Human Services, $2020 \mathrm{~b})$. One of the more common strategies $(n=7)$ was to encourage more frequent virtual contact than would be required for in-person face-to-face contacts monthly. Video contact was often preferred over telephone contact (Nebraska, Idaho, Oregon, Wisconsin). In other states, telephone would not count towards a face-to-face contact with a child in foster care (Kentucky, Minnesota, New Mexico, Tennessee).

\section{Adoption}

Six states specifically discussed the impact of COVID-19 on face-to-face contacts related to adoption processes. Processes discussed included the adoption process $(n=4)$, post-placement supervision visits $(n=2)$, and adoption relinquishments $(n=1)$. Several aspects of face-to-face contact related to the adoption process were discussed including home evaluations, court proceedings, and meetings to discuss the placement. In North Dakota, home visits for adoption placement were encouraged to "continue to the greatest extent possible" while following precautions (North Dakota Department of Human Services, 2020a, para. 2). In California and Ohio, post-placement visits could be held face-to-face or through virtual contact based upon the 
specifics of the case (California Department of Social Services 2020a; Ohio Department of Job and Family Services, 2020). One state (California) discussed adoption relinquishments and recommended "postponing the acceptance of relinquishments until face-to-face visits resume" as virtual contact would not be conducive to this sensitive process (California Department of Social Services, 2020a, p. 13).

\section{General Child Welfare}

Three subthemes emerged that impacted a broader range of child welfare service provision: high risk individuals, documentation, and return to in-person contact.

\section{High Risk Individuals}

Twelve states mentioned limiting child-case manager inperson interactions for children at higher risk for complications related to COVID-19. Six states discussed the needs of limiting contact with vulnerable children in foster care or on child welfare caseloads (Arizona, Florida, Kentucky, Illinois, North Dakota, Texas). Each state supported the need to prevent contact and some specifically mandated virtual contact only. For example, Kentucky stated, "Every precaution should be taken to ensure that children and youth with underlying medical conditions are not exposed to COVID $19 . .$. there should be no interaction between these children and others with whom they do not reside" (Kentucky Department of Community Based Services, 2020b, p. 5). Three states discussed limiting the number of contacts with congregate care through the use of a point person approach (Illinois, Massachusetts, Ohio). In this approach, a single case manager would make face-to-face contact with numerous children at one facility rather than each child's individual case manager coming to meet with them. This approach would decrease the number of different people coming into the facility and reduce potential exposure.

Four states broadly addressed the needs of client families (Indiana, Nevada, North Dakota, Oregon). Arizona specifically mentioned the needs of foster families who had a high-risk individual in the home who might not be the foster child (Arizona Department of Child Safety, 2020a). In addition, five states discussed protecting employees at higher risk for complications related to COVID-19 (Indiana, Massachusetts, Nevada, North Carolina, North Dakota). Strategies to do that included assigning these case managers to virtual face-to-face contacts. New Jersey had a unique approach that was not described in any other state. New Jersey created a COVID-19 response team for each jurisdiction in the state "utilizing paid, volunteer CPP field staff from local and area offices" that were "responsible for conducting investigations and home visits to open and highrisk families" (New Jersey Department of Children and
Families, 2020, p. 1). This unique approach limited the number of employees who would be exposed and limiting the exposure of community members to larger numbers of individuals.

\section{Documentation}

In four states, the procedures for how to document virtual contacts for this early time period in the pandemic were described (Kentucky, North Dakota, Oregon, Wisconsin). At that point, case managers were asked to $\log$ virtual contacts as face-to-face contacts because virtual contacts were not an option in the system or because it would not have been sufficient to indicate contact was made that month. While detail was typically added in the notes section, this system of documentation should be noted for any future administrative data analysis because it will be difficult to distinguish outcomes for cases with in-person contact from cases with virtual contact until administrative systems catch up with this policy change. Documentation is likely a wide-spread issue, impacting more than these four states.

\section{Return to In-person Contact}

At the timing of this review, three states (Idaho, Nebraska, Texas) included information about their return to face-toface contacts on foster care caseloads. Starting on May 1, 2020, Texas "resumed all in-person unannounced 24-hour awake night supervision monitoring visits" and in-person "visits to facilities or homes with more than six children" (Texas Department of Family and Protective Services, 2020, para. 1). On May 13, 2020, Nebraska began transitioning back to in-person contacts with families and children served through foster care (Nebraska Department of Health and Human Services, 2020). On May 18, 2020, Idaho began making monthly contacts in-person with children in foster care (Idaho Department of Health and Welfare, 2020).

\section{Discussion}

Documents indicated that states used a range of strategies to operate child welfare services during the COVID-19 pandemic. While some states encouraged virtual contact to meet face-to-face standards, other states encouraged case managers to make face-to-face contacts in-person. These variations may reflect actual rates of COVID-19 spread or community perception of spread during the earliest stages of the pandemic. There were also differing opinions on what a quality contact looked like and what technology could be used to make that contact (e.g., video vs. telephone). Child welfare agencies tried some creative strategies to attempt to 
address safety, permanency, and well-being among the families they serve. This must be commended given the lack of U.S. preparation for this type of public health emergency and the need to pivot quickly to provide child welfare services under new circumstances. However, with low levels of federal guidance on the matter, states had to develop new strategies quickly in order to serve families. Additional funding for technology, better access to internet in rural communities, and more formalized plans to address face-toface contacts would be beneficial strategies to support child welfare's service provision if a pandemic or similar public emergency were to occur in the future.

The US child welfare system emphasizes the importance of prioritizing the needs of families and "families are recognized as experts in determining what is best for themselves and their children" (ACF, 2021, para. 1). However, family preferences did not come up as frequently in our analysis as would be expected. Based on documentation located for this analysis, much of the emphasis during these early months of the COVID-19 pandemic was on attempting to meet child welfare standards for contact with families and children in order to address safety and agency standards. Documentation in Colorado, Illinois, and Iowa mentioned the role of family preferences in deciding whether or not to hold meetings in-person or virtually (Colorado Office of Children, Youth and Families, 2020; Illinois Children and Family Services, 2020; Iowa Department of Human Services, 2020). These examples may indicate that family preferences were incorporated into practice in other states as well and that case managers' used discretion into how to implement policy while being sensitive to family needs. However, documentation clarifying the role that family preferences play in these decisions is also needed. While there were some examples of how family preferences were incorporated into these decisions, findings from this analysis indicate that child welfare documentation was primarily focused on how to address short term contact standards in the early stages of the pandemic. During the months of March through May of 2020, the United States and other countries around the world were still trying to understand how long it would take to return to our pre-COVID ways of living as individuals and within our communities. Short term logistics for how to make these sudden changes were a focus during this period. Future work should examine how family preferences were incorporated into decision making over time. Research examining how case managers within these state agencies were able to promote and maintain bonds between families of origin and children in foster care would also be valuable.

As child welfare agencies and the clients they serve become more familiar with the use of video networking platforms, there is the potential that these types of contacts could be used regularly by child welfare to talk and engage with families more often or for specific types of checks like demonstrating there is food in the home, showing that specific rooms have been cleaned, or allowing a case manager to participate in happy times in a child's life. These contacts also encourage child welfare agencies to support the access of families to technology that is limited for some individuals living in poverty or in rural areas. While several states discussed how to work with families if they do not have the technology necessary to use videoconferencing, very little was said about actually helping families acquire laptops, phones, or cameras. This type of in-kind support has the potential to help child welfare-involved families better engage with the child welfare system; but there is also the potential to decrease overall stress families experience attempting to find new jobs and homeschool their children during a pandemic without working computers or phones. Even when families have the technology to access the internet, many communities do not have consistent internet access at home to allow them to effectively communicate through video conferencing. This crisis has really highlighted the credible need for technology access and technology education for individuals in low-income communities and for older adults.

In order to understand the outcomes related to these practices, quantitative analyses should examine types of contact and outcomes of child safety during the pandemic. Unfortunately, during the earliest months of COVID-19, this will be difficult due to the ways administrative data systems logged contact method. There was evidence from several states that both virtual and in-person contacts were logged as face-to-face contacts, as both counted towards monthly required contacts following the child welfare policy changes (ACF, March 18, 2020; Milner, April 15, 2020). It is critical that state systems begin logging child welfare face-to-face contacts into different categories (virtual and in-person) in order to support evaluation down the road.

Additional practice questions need to be addressed to support the highest quality contacts in the field; including: What are the best ways to engage families virtually for a child welfare assessment, family preservation case, or monthly contacts for children in foster care? How can families be engaged in a virtual home evaluation for licensing or child safety assessments? Is video conferencing better at supporting child safety than phone conversations? How often should virtual contacts be made to promote safety? Under what circumstances is an in-person contact necessary?

While this study is the first to examine face-to-face child welfare contacts during the COVID-19 pandemic, it has several limitations. First, the sample did not include caseworker statements about how they actually implemented face-to-face contact policies in their work. These reviewed 
documents were available during the early stages of the pandemic and provided guidance to states about their casework. Further research is needed to examine the impact of these policies on practice. While the majority of U.S. states have a centralized administration of their child welfare system, nine states (California, Colorado. North Carolina, Virginia, New York, Pennsylvania, Ohio, North Dakota, Minnesota) have a county administered child welfare system and two additional states have a hybrid administered system in which the state and counties share this role (Wisconsin, Nevada) (Child Welfare Information Gateway, 2018). It is possible that additional information would have been available at the county level in these states. However, with a combined 718 counties in these 11 states, it was not feasible to consider a county-level analysis for these states. Although a thorough systematic search was conducted, this study is limited to documents that were publicly available and accessible online. Additional documents may have been distributed internally or may have only been available on a shared state server that was not accessible to the researchers. As such, this search represents a point-in-time snapshot of state documents publicly available between 5/9/20 and 5/21/20. While many states in the sample maintain a historical $\log$ of these updates that allowed the researchers to observe a history of recommendations, there were other states with limited or no information on the topic. It is possible that some information had already been removed for these states, or that earlier versions of text had been replaced by updated text. Despite these limitations, this study contains the most comprehensive information on child welfare's response to COVID-19 that is known to this research team.

This study highlights a range of strategies used in child welfare as an opportunity for states to consider their individual policies and practices. By reviewing previous practice and hearing what other states are doing, child welfare agencies have the potential to strengthen their plans should virtual contact be utilized again in the future.

Funding Work on this article by Kristen Seay was supported in part by the National Institute of General Medical Sciences of the National Institutes of Health for the UofSC Research Center for Child WellBeing under Award Number P20GM130420. The content is solely the responsibility of the authors and does not necessarily represent the official views of the National Institutes of Health.

\section{Compliance with Ethical Standards}

Conflict of Interest The authors declare no competing interests.

Ethical Approval This article does not meet criteria for human subjects review given that it involves the review of publicly available documents and no data was collected from human subjects.
Publisher's note Springer Nature remains neutral with regard to jurisdictional claims in published maps and institutional affiliations.

\section{References}

Administration for Children \& Families Children's Bureau. (2021, April 19). Engaging Families. https://www.childwelfare.gov/ topics/famcentered/engaging/.

Administration for Children and Families. (2007). Child Welfare Policy Manual. https://www.acf.hhs.gov/cwpm/public_html/ programs/cb/laws_policies/laws/cwpm/policy_dsp_pf.jsp.

Administration for Children and Families. (March 18, 2020). Child Welfare Policy Manual section 7.3 TITLE IV-B, Programmatic Requirements, Question \#8. https://www.acf.hhs.gov/cwpm/ public_html/programs/cb/laws_policies/laws/cwpm/policy_dsp_ pf.jsp?id=7.

Adoption and Foster Care Analysis and Reporting System. (2020). The AFCARS Report: Preliminary FY 2019 Estimates. https://www. acf.hhs.gov/sites/default/files/documents/cb/afcarsreport27.pdf.

Alaska Department of Health and Social Services. (2020a, May 15). For Parents Involved with OCS: Frequently Asked Questions During the COVID-19 Crisis. http://dhss.alaska.gov/ocs/ Documents/FosterCare/FosterParentFAQsCOVID19.pdf.

Alaska Department of Health and Social Services. (2020b, May 15). Foster Parent FAQs. http://dhss.alaska.gov/ocs/Documents/ FosterCare/FosterParentFAQsCOVID19.pdf.

American Academy of Pediatrics. (2020). Guidance on Providing Pediatric Well-care During COVID-19. https://services.aap.org/ en/pages/2019-novel-coronavirus-covid-19-infections/clinicalguidance/guidance-on-providing-pediatric-well-care-duringcovid-19/.

Arizona Department of Child Safety. (2020a, May 15). COVID-19 Coronavirus - A message for Caregivers \#3 March 18, 2020. https://dcs.az.gov/news/covid-19-coronavirus-message-ca regivers-3.

Arizona Department of Child Safety. (2020b, May 15b). Requirements for Monthly DCS Specialist Contact with Children. https://dcs.az. gov/sites/default/files/documents/files/031920ChildConta ctAdministrativeDirective.pdf.

Boserup, B., McKenney, M., \& Elkbuli, A. (2020). Alarming trends in US domestic violence during the COVID-19 pandemic. The American Journal of Emergency Medicine, 38(12), 2753-2755.

Bowen, G. A. (2009). Document analysis as a qualitative research method. Qualitative Research Journal, 9(2), 27-40.

Bruskas, D. (2008). Children in foster care: a vulnerable population at risk. Journal of Child and Adolescent Psychiatric Nursing, 21(2), 70-77.

Bryant, D. J., Oo, M., \& Damian, A. J. (2020). The rise of adverse childhood experiences during the COVID-19 pandemic. Psychological Trauma: Theory, Research, Practice, and Policy.

California Department of Social Services. (2020a, May 15). All County Letter No. 20-25. https://www.cdss.ca.gov/Portals/9/AdditionalResources/Letters-and-Notices/ACLs/2020/ACL20-25.pdf.

California Department of Social Services. (2020b, May 15). All County Letter No. 20-43. https://www.cdss.ca.gov/Portals/9/ Additional-Resources/Letters-and-Notices/ACLs/2020/20-43.pdf.

Capacity Building Center for States. (2017). Defining Quality Contacts (Quality Matters: Improving caseworker contacts with children, youth, and families, Issue. https://capacity.childwelfare.gov/sta tes/resources/defining-quality-contacts/.

Centers for Disease Control and Prevention. (2020a). Coronavirus Disease 2019. https://www.cdc.gov/media/releases/2020/s0528coronavirus-death-toll.html. 
Centers for Disease Control and Prevention. (2020b). Coronavirus Disease 2019 (COVID-19). https://www.cdc.gov/coronavirus/ 2019-ncov/need-extra-precautions/people-at-higher-risk.html.

Centers for Disease Control and Prevention. (2020c). Coronavirus Disease 2019 (COVID-19) Prevention \& Treatment. https://www.cdc. gov/coronavirus/2019-ncov/prevent-getting-sick/prevention.html.

Child and Family Services Improvement Act of 2006, Pub. L. 109288, § 120 Stat. 1233. (2006).

Child and Family Services Improvement and Innovation Act of 2011, Pub. L. 112-34. (2011).

Child Welfare Information Gateway. (2015). Health-care coverage for youth in foster care-and after. U.S. Department of Health and Human Services, Children's Bureau. https://www.childwelfare. gov/pubPDFs/health_care_foster.pdf.

Child Welfare Information Gateway. (2018). State vs. county administration of child welfare services. U.S. Department of Health and Human Services, Children's Bureau. https://www.childwelfare. gov/pubs/factsheets/services/.

Children's Bureau. (2020). How the child welfare system works. https://www.childwelfare.gov/pubs/factsheets/cpswork.

Cohen, R. I. S., \& Bosk, E. A. (2020). Vulnerable youth and the COVID-19 pandemic. Pediatrics, 146(1) https://doi.org/10.1542/ peds.2020-1306.

Colorado Office of Children Youth \& Families. (2020, May 15). Resources for CO Counties in Response to COVID-19. https://www.coloradocwts.com/covid-19.

Coulton, C. J., Crampton, D. S., Irwin, M., Spilsbury, J. C., \& Korbin, J. E. (2007). How neighborhoods influence child maltreatment: a review of the literature and alternative pathways. Child Abuse \& Neglect, 31(11), 1117-1142.

Dooley, D. G., Bandealy, A., \& Tschudy, M. M. (2020). Low-income children and coronavirus disease 2019 (COVID-19) in the US. JAMA Pediatrics.

Emig, C. (2020). COVID-19's forgotten children. Child Trends. https://www.childtrends.org/covid-19s-forgotten-children.

Greer, S. L., King, E. J., da Fonseca, E. M., \& Peralta-Santos, A. (2020). The comparative politics of COVID-19: the need to understand government responses. Global Public Health, 15(9), $1413-1416$.

Griffith, A. K. (2020). Parental burnout and child maltreatment during the COVID-19 pandemic. Journal of Family Violence, 1-7.

Idaho Department of Health and Welfare (2020). Guidance for Social Worker Contacts and Parent/Child Visits During COVID-19.

Illinois Children and Family Services. (2020, May 15). Coronavirus of COVID-19. https://www2.illinois.gov/dcfs/brighterfutures/hea lthy/Pages/Coronavirus.aspx.

Illinois Department of Children \& Family Services. (2020, May 15). Memo: COVID-19 and Modifications to In-person Contact Requirements. https://www2.illinois.gov/dcfs/brighterfutures/hea lthy/Documents/Director_Guidance_to_Workers_Modifications_ to_In-person_Contact_Requirements_032020.pdf\#search = COVID\%2D19\%20and\%20Modifications\%20to\%20In\% 2Dperson\%20Contact\%20Requirements.

Indiana Department of Child Services. (2020a, May 15). Community Based Services $Q \& A$. Retrieved May 15, 2020 from https://www. in.gov/dcs/files/coronavirus_faq_community_based_services.pdf.

Indiana Department of Child Services. (2020b, May 15). March 20, 2020 Memo: COVID-19 Update. https://www.in.gov/dcs/files/ COVID-19_Field_Update_2020.03.20.pdf.

Iowa Department of Human Services. (2020, May 1). Home Visitation and Contact Guidance in Response to COVID-19 for Child Welfare Family-Centered Services: May 1, 2020.

Kentucky Cabinet for Health and Family Services. (2020, March 18). Protection and Permanency Information Memorandum, 20-02.

Kentucky Department of Community Based Services. (2020a, May 16a). COVID-19 - State of Emergency - Investigation Initiation
Guidance for Child Protective Services. https://manuals.sp.chfs. ky.gov/Resources/Related\%20Resources\%20Library/COVID\% 2019\%20CPS\%20Guidance.docx.

Kentucky Department of Community Based Services. (2020b, May 16b). COVID-19 Frequently Asked Questions (FAQ) for Out of Home Care Providers Updated 3/25/2020. https://manuals.sp. chfs.ky.gov/Resources/Related\%20Resources\%20Library/ COVID-19\%20FAQ\%20for\%20OOHC\%20Providers.pdf.

Van Lancker, W., \& Parolin, Z. (2020). COVID-19, school closures, and child poverty: a social crisis in the making. The Lancet Public Health, 5(5), e243-e244.

Lee, A. (2020). COVID-19 and the Advancement of Digital Physical Therapist Practice and Telehealth. Physical Therapy.

Linneberg, M. S., \& Korsgaard, S. (2019). Coding qualitative data: A synthesis guiding the novice. Qualitative research journal.

Michigan Department of Health \& Human Services. (2020, May 15). COVID-19 Response: Updated interim caseworker guidance for face-to-face contacts, parenting time and sibling visits for children's services agency and contracted child placing agencies UPDATED. https://www.michigan.gov/documents/mdhhs/CI_ 20-032_COVID-19_Response-Updated_Interim_Caseworker_ Guidance_for_Face_to_Face_Contacts_and_Parenting_TimeSibling_Visits_for_686210_7.pdf.

Milner, J. (2020). Guidance regarding fingerprint and caseworker visit requirements during COVID-19 response. https://www.acf. hhs.gov/sites/default/files/cb/stafford_act.pdf.

Minnesota Department of Human Services. (2020, May 14). Bulletin Number 20-68-13: Modify timelines and face-to-face requirements for Child Protection responses to alleged maltreatment. https://www.dhs.state.mn.us/main/groups/publications/ documents/pub/dhs-320448.pdf.

Missouri Department of Social Services: Children's Division. (2020, May 13). COVID-19 PANDEMIC Temporary Policy: 5/16/2020. https://dss.mo.gov/covid-19/pdf/temporary-policy-in-Responseto-COVID-19.pdf.

Nebraska Department of Health and Human Services. (2020, May 15). Guidance on Child, Family and Facility Contact During the COVID-19 Public Health Emergency, 5/ $13 / 2020$.

New Hampshire Division for Children Youth and Families. (2020, May 18). Letter to DCYF Staff Regarding In-Person Child, Youth, and Family Contact May 15, 2020. https://www.dhhs.nh. gov/dcyf/documents/dcyf-covid-visit-directive.pdf.

New Jersey Department of Children and Families. (2020, May 13). Division of Child Protection \& Permanency Summary Guidelines, Issued 3/20/20 - Updated 4/17/20.

North Carolina Department of Health and Human Services. (2020, May 13). Child Protective Services Guidance COVID-19. https:// covid19.ncdhhs.gov/media/256/open.

North Dakota Department of Human Services. (2020a, May 13). Children and Family Services Division-Adoption Coronavirus (COVID-19) Frequently Asked Questions. https://www.nd.gov/ dhs/info/covid-19/docs/covid-19-faq-adoption.pdf.

North Dakota Department of Human Services. (2020b, May 13). Children and Family Services Division Coronavirus (COVID-19) Frequently Asked Questions. https://www.nd.gov/dhs/info/covid19/docs/covid-19-faq-children-family-services.pdf.

O'Leary, Z. (2014). The essential guide to doing your research project. 2nd ed. SAGE Publications, Inc.

Ohio Department of Job and Family Services. (2020, May 6). ODJFS Coronavirus (COVID-19) Response Frequently Asked Questions, Updated: May 6, 2020.

Oklahoma Human Services. (2020, March 16). Resource Parents: COVID-19, RE: Coronavirus Disease (COVID-19). https://www. ourokdhs.org/s/blogs/dear-resource-parentsMCVH4XAPNALNFUBFVJDE4B4PAC5Y. 
Oregon Department of Human Services. (2020, May 12). COVID-19 Recommendations for Permanency Work. https://www.oregon. gov/dhs/CHILDREN/Documents/08\%20-\%20COVID\%2019\% 20Guidance $\% 20$ for $\% 20$ Contact $\% 20$ in $\% 20$ Permanency $\% 20$ Work \%203.24.20.pdf.

DePanfilis, D., \& Salus, M. K. (2003). Child Protective Services: A guide for caseworkers. U.S. Department of Health and Human Services, Administration for Children and Families.

Posick, C., Schueths, A. A., Christian, C., Grubb, J. A., \& Christian, S. E. (2020). Child victim services in the time of COVID-19: new challenges and innovative solutions. American Journal of Criminal Justice, 45(4), 680-689.

Prime, H., Wade, M., \& Browne, D. T. (2020). Risk and resilience in family well-being during the COVID-19 pandemic. American Psychologist, 75(5), 631-643.

Rispens, S. (2020). Montana DPHHS experiencing fewer calls to child abuse hotline amid COVID-19 pandemic. Great Falls Tribune. Retrieved May 19, 2020 from https://www.greatfallstribune.com/ story/news/education/2020/04/16/montana-dphhs-experiencingfewer-calls-child-abuse-hotline-amid-covid-19-pandemic-corona virus $/ 5146081002 /$.

Seay, K. D. (2020). Pathways from parental substance use to child internalizing and externalizing behaviors in a child protective services sample. Child Maltreatment, 25(4), 446-456.

Seay, K. D. \& Kohl, P. L. (2015). The comorbid and individual impacts of maternal depression and substance dependence on parenting and child behavior problems. Journal of Family Violence, 30(7), 899-910.
Seay, K. D., Iachini, A. L., DeHart, D. D., Browne, T. \& Clone, S. (2017). Substance abuse treatment engagement among mothers: Perceptions of the parenting role and agency-related motivators and inhibitors. Journal of Family Social Work, 20(3), 196-212.

Shanahan, M. (2010). Cross-sectional design. In A. Mills, Durepos, G., \& Wiebe, E. (Ed.), Encyclopedia of case study research (pp. 268-269). SAGE Publications, Inc.

Texas Department of Family and Protective Services. (2020, May 12). Message to RCC Providers: May 6, 2020. https://www.dfps.state. tx.us/About_DFPS/Coronavirus/rcc.asp.

Turney, K., \& Wildeman, C. (2017). Adverse childhood experiences among children placed in and adopted from foster care: Evidence from a nationally representative survey. Child Abuse \& Neglect, $64,117-129$.

Washington Department of Children Youth \& Families. (2020, May 14). Combined in-home services provider tip sheet for remote services. https://www.dcyf.wa.gov/sites/default/files/pubs/CWP_0053.pdf.

Webster, P. (2020). Virtual health care in the era of COVID-19. The Lancet, 395(10231), 1180-1181.

Wong, C. A., Ming, D., Maslow, G., \& Gifford, E. J. (2020). Mitigating the impacts of the COVID-19 pandemic response on atrisk children. Pediatrics, 146(1) https://doi.org/10.1542/peds. 2020-0973.

World Health Organization (2020). Coronavirus. Accessed June 10, 2020, from https://www.who.int/westernpacific/health-topics/ coronavirus.

Worldometer (2020). Coronavirus Update: Deaths from COVID-19 Virus Pandemic. Accessed June 10, 2020. https://www. worldometers.info/coronavirus/. 